\title{
AVALIAÇÃO DA QUALIDADE DA ÁGUA DO AÇUDE GRANDE NA CIDADE DE CAJAZEIRAS-PB
}

\author{
WATER QUALITY ASSESSMENT OF AÇUDE GRANDE IN THE CITY \\ OF CAJAZEIRAS-PB
}

\author{
Kildery Ângelo Marias Rolim ${ }^{1}$ \\ Maria Aparecida Bezerra Oliveira ${ }^{2}$ \\ Guilherme Urquisa Leite ${ }^{3}$ \\ Hellykan Berliet dos Santos Monteiro ${ }^{4}$ \\ Fernando Chagas de Figueiredo Sousa ${ }^{5}$ \\ Thalita Maria Ramos Porto ${ }^{6}$
}

\footnotetext{
${ }^{1}$ Graduando em Engenharia Civil pela Faculdade Santa Maria - FSM.

${ }^{2}$ Possui graduação em Ciência e Tecnologia e em Engenharia Civil pela Universidade Federal Rural do Semi-Árido - UFERSA (2011-2016). Especialista em docência do ensino superior (2017-2018) pela Faculdade Santa Maria. Mestrado em Sistemas Agroindustriais com linha de pesquisa em recursos hidricos e saneamento ambiental (2017) Pela Universidade Federal de Campina Grande-UFCG. Docente no curso de Graduação em Engenharia Civil da Faculdade Santa Maria - Cajazeiras - PB. Atua na área de Resíduos Sólidos e Recursos Hidricos, é responsável pelas unidades curriculares de materiais de construção civil II, introdução a engenharia civil e eletrotécnica geral.

${ }^{3}$ Possui graduação em Engenharia Civil pela Universidade Federal da Paraíba (2011) e mestrado em Engenharia Civil e Ambiental pela Universidade Federal da Paraíba (2016). Atualmente é docente do curso de bacharelado em Engenharia Civil da Faculdade Santa Maria, responsável pelas unidades curriculares de Eletrotécnica, Instalações Elétricas Prediais, Instalações Hidrossanitárias, Estradas e Transporte I e II e Concreto Protendido e Pré-moldado.

${ }^{4}$ Possui graduação em Engenharia Civil pela Universidade Federal de Campina Grande (UFCG/ 2014), Mestrado em Estruturas com ênfase em materiais de construção pelo Programa de PósGraduação em Engenharia Civil (PPGEC/ 2017) da Universidade Federal de Pernambuco. Trabalha como Professora na Faculdade Santa Maria - FSM, é responsável pelas unidades curriculares de estruturas de concreto armado, resistência dos materiais I e estática das construções I e estruturas metálicas e de madeira.

${ }^{5}$ Engenheiro Civil graduado pela Universidade Federal de Campina Grande - UFCG, Epecialista em Perícia Ambiental, Mestre em Sistemas Agroindustriais (UFCG), com atuação profissional na área de Construção Civil (Acompanhamento e perícia) e de geotecnia (estradas e rodovias). Professor da Faculdade Santa Maria, Cajazeiras - PB, responsáveis pelas unidades curriculares de construção civil, planejamento de obras, introdução ao bim e projeto arquitetônico.

${ }^{6}$ Engenheira civil (2015), formada pela Universidade federal de Campina Grande- UFCG. Atuei como engenheira júnior no ano de 2016 na Construtora Norte Nordeste ME Ltda, realizando fiscalização e gerenciamento de obras. Mestre (2018) em Engenharia Civil e Ambiental (PPGECA? UFCG) e Doutoranda em Engenharia Civil e Ambiental pela UFCG. Sou professora desde 2016, lecionei em instituições de ensino técnico como Grau Técnico e Infogenius, responsável por disciplinas nas áreas da construção civil. Atualmente, sou professora com dedicação exclusiva na Faculdade Santa Maria, lecionando disciplinas direcionadas ao curso de engenharia civil, de nível profissional. Também atuo na Faculdade Santa Maria como coordenadora de estágio do curso de engenharia civil.
} 
RESUMO: Objetivo: Esta pesquisa pretende fazer uma análise da qualidade da água, através das propriedades físico-químicas, oriunda do Açude Grande no município de Cajazeiras-PB. Metodologia: Foram coletadas amostras de água em cinco pontos do açude, as quais foram analisadas segundo os seguintes parâmetros: Oxigênio Dissolvido (OD), Demanda Bioquímica de Oxigênio (DBO), Temperatura, pH, Nitrogênio Total, Fósforo Total e Turbidez. As análises foram realizadas no laboratório de saneamento da Faculdade Santa Maria - FSM. Resultados: Com a ausência da fiscalização, junto à falta de compromisso por parte da gestão pública, as invasões de construções em torno do açude foram primordiais para o despejo de lixos e efluentes, onde, devido à falta de um sistema de saneamento adequado, o açude tornou-se um local de despejo de esgotos domésticos. O açude possui um grande potencial hídrico e, por este motivo, é de grande importância sua revitalização, trazendo de volta 0 benefício do abastecimento em tempos de seca. Conclusão: Pelos fatos mencionados, é de vital importância um projeto de lei municipal que fiscalize construções irregulares nas margens do açude, o controle de resíduos, desviando as galerias de esgoto para uma estação de tratamento de água, e implantações de um plano de resíduos sólidos.

Descritores: Análise da água. Contaminação da água. Reaproveitamento.

ABSTRACT: Objective: This research aims to make an analysis of the quality of water, through the physical-chemical properties, stemming from Açude Grande in the city of Cajazeiras-PB. Methodology: water samples were collected at five points of the weir, which were analyzed according to the following parameters: Dissolved Oxygen (DO), Biochemical Oxygen Demand (BOD), Temperature, $\mathrm{pH}$, total nitrogen, total phosphorus and turbidity. The analyses were performed at the Laboratory of Sanitation of the College Santa Maria - FSM. Results: In the absence of supervision, along with the lack of commitment on the part of public management, the invasions of buildings around the weir were crucial for the dumping of waste and effluents, where, due the lack of an adequate sanitation system, the weir became a place of eviction of domestic sewage. The weir has a large water potential and, for this reason, its revitalization is of great importance, bringing back the benefit of supply in times of drought. Conclusion: the aforementioned facts make a project of municipal law of vital importance, controlling irregular constructions on the weir banks, the waste, diverting the galleries of sewage for a water treatment station, and the deployments of a plan for solid waste management.

Descriptors: Analysis of the water. Water contamination. Reuse. 


\section{INTRODUÇÃO}

A necessidade primordial para a vida é, sem dúvida, a água, recurso natural indispensável a todos os seres vivos, além de suporte essencial aos ecossistemas. É retirada de rios, lagos, represas e aquíferos, tendo influência direta sobre a saúde, a qualidade de vida e o desenvolvimento das populações (SILVA et al., 2017). Porém, a mesma está se tornando cada vez mais escassa, mesmo com o racionamento e inúmeras campanhas educativas na tentativa de economizar esse bem tão precioso.

Aproximadamente $97,5 \%$ da água que existe é salgada. Entre os $2,5 \%$ do volume restante, há ainda muita água que não é salgada, mas que não é propriamente doce. É a chamada água salobra, o que significa que é "um pouco" salgada. Essa água salobra pode ser encontrada em alguns lagos, lagoas, deltas, pântanos e até no solo (BRASIL, 2019).

O abastecimento de água teve inúmeros avanços nos últimos tempos, ainda assim, cerca de 36 milhões de pessoas ainda não têm acesso à água potável na América Latina, sendo que $80 \%$ destes residem em áreas rurais. No Brasil, o déficit de cobertura de sistemas de tratamento de água e esgoto na zona rural é grande, aproximadamente $67 \%$ da população capta água de fontes alternativas, que, geralmente, são inadequadas para consumo humano, e 66\% lançam os dejetos em fossas rudimentares ou diretamente no solo ou nos cursos d'água (CARVALHO et al., 2017).

Observa-se a crescente contaminação da água, sendo que a prática mais comum ocorre com o despejo de poluentes, que acontece com bastante frequência em locais onde não existe tratamento da água, tornando prejudicial à saúde da população.

A preocupação mundial, atualmente, está voltada para a qualidade da água para consumo humano, uma vez que o desenvolvimento das cidades e o aumento 
populacional acabaram influenciando diretamente no aumento da poluição e degradação dos recursos naturais (GLÓRIA; HORN; HILGEMANN, 2017).

A Resolução CONAMA № 357, de 17 de março de 2005, dispõe sobre a classificação dos corpos de água e diretrizes ambientais para o seu enquadramento, bem como estabelece as condições e padrões de lançamento de efluentes e dá outras providências. A mesma estabeleceu, no Art. $2^{\circ}$ do seu anexo, cujo título é Norma de Qualidade da Água para Consumo Humano, que "toda a água destinada ao consumo humano deve obedecer ao padrão de potabilidade e está sujeita à vigilância da qualidade da água". (BRASIL, 2005).

Mediante a escassez hídrica e a seca que castiga a região nordeste, onde está inserida a cidade de Cajazeiras no estado da Paraíba, torna-se relevante avaliar e classificar as fontes hídricas existentes, de modo a direcionar seu melhor aproveitamento, podendo ser usadas, depois de tratadas, em épocas de seca.

Portanto, o objetivo deste trabalho é analisar e comparar os resultados das amostras de cinco pontos do Açude Grande no município de Cajazeiras-PB, para que, desta forma, seja possível classificar o açude com base na resolução no 357/2005 do CONAMA.

\section{METODOLOGIA}

Para a realização desta pesquisa, analisou-se o açude Senador Epitácio Pessoa, conhecido popularmente como Açude Grande, localizado na cidade de Cajazeiras, no estado da Paraíba. O local de estudo em questão é caracterizado por apresentar uma área de aproximadamente $421.633,58$ metros quadrados, dispondo ainda de uma capacidade que chega aos 2.599.600 metros cúbicos de água.

A primeira etapa foi a coleta das amostras, realizada no mês de maio de 2019. Foram previamente definidos cinco pontos, identificados de 1 a 5 .

A escolha dos pontos deu-se da seguinte forma: os pontos 1 e 2 foram escolhidos por estarem próximos à área de lazer, a Praça do Leblon, onde podem ser facilmente despejados lixos nas margens do açude pelas pessoas que circulam 
naquele local; os pontos 3 e 4, devido ao despejo de efluentes no local; e o ponto 5 foi determinado pelo fato de visualmente não ter despejo de efluentes e ser distante do fluxo de pessoas.

Para coleta, foram tomados alguns cuidados, seguindo as recomendações do Guia Nacional de coleta e preservação de amostras: água, sedimento, comunidades aquáticas e efluentes líquidas (Brasil, 2011).

Após a coleta das amostras, seguiu-se para o laboratório de saneamento da Faculdade Santa Maria (FSM) para análises dos parâmetros, onde foram realizadas duas medições para cada ponto. Posteriormente, foi realizada uma média com os valores obtidos nas duas medições de cada parâmetro em cada ponto, onde as médias foram usadas nas representações de cada parâmetro a fim de ter um valor mais preciso. Por meio do valor obtido através da média, foi realizada a classificação do açude mediante a comparação dos parâmetros contidos na Resolução CONAMA no 357/2005 e dos resultados das amostras de campo.

As análises dos parâmetros de pH e Oxigênio Dissolvido foram realizadas no laboratório imediatamente após a coleta das amostras, isso ocorreu devido a processos burocráticos para autorização e a liberação do equipamento em tempo hábil para as análises em campo. Quanto aos pontos analisados para o parâmetro DBO, as análises foram realizadas apenas nos pontos 1 e 2. Essa medida foi necessária, pois o ensaio para determinação de DBO necessitaria de cinco dias para sua conclusão, tempo este indisponível para a finalização do estudo.

A média dos resultados encontrados nas análises foram comparadas com os valores limites estabelecidos na Resolução CONAMA nํ 357/2005, onde foi possível a classificação do açude quanto ao tipo de água e a classe, e, assim, traçar alternativas de utilização da água.

Para a realização do ensaio, foram utilizados cubetas, água destilada, papel toalha e o turbidímetro, aparelho constituído de um nefelômetro, sendo expresso seu resultado em unidades nefelométricas de turbidez (UNT).

Foi realizada a calibração do aparelho de acordo com as instruções estabelecidas pelo fabricante, disponível no manual da empresa AlfaKit. Logo depois de realizar a calibração, agitou-se a amostra a ser ensaiada com objetivo de dispersar os sólidos, e, após o desaparecimento de bolhas de ar, foi feita uma 
limpeza na cubeta, e a amostra foi inserida no equipamento para determinar a turbidez.

Para a leitura das amostras, foi utilizado o pHmetro, aparelho constituído de um eletrodo de $\mathrm{pH}$, a sonda de temperatura, e o bequer, sendo expresso seu resultado em $\mathrm{pH}$ (potencial hidrogeniônico).

Inicialmente, foi realizada a calibração do aparelho pHmetro (Figura 8). O eletrodo foi higienizado com água destilada e mergulhado na solução tampão com $\mathrm{pH}$ igual a quatro. Posteriormente, realizaram-se, mais uma vez, a higienização do eletrodo e mergulha em outra solução tampão com pH de sete. Logo após a calibração do aparelho, foi introduzida a amostra para ser analisada. Desta forma, foram obtidos os resultados das amostras.

Para a realização do ensaio, foram seguidas as recomendações realizadas pelo manual da empresa AlfaKit.

Após calibração, apareceram os valores de oxigênio. Sendo assim, o equipamento já estava apto a ser utilizado para a realização das leituras. Para a realização do ensaio, foram adicionados $300 \mathrm{ml}$ da amostra em um béquer e, posteriormente, mergulhada a sonda na amostra, a qual foi agitada de forma leve. Então, foi aguardado aproximadamente um minuto até ocorrer o equilíbrio térmico entre a amostra e a sonda. O resultado obtido a partir do ensaio de Oxigênio Dissolvido é expresso em $\mathrm{mg} / \mathrm{l}$.

Mediram-se $20 \mathrm{ml}$ de amostra com a proveta, posteriormente transferidos para o Erlenmeyer. Logo após esse processo, foi realizada uma prova em branco, contendo $20 \mathrm{ml}$ de água desionizada e sendo adicionada em outro Erlenmeyer. Posteriormente, foram adicionados nas duas amostras citadas acima os reagentes.

Foram adicionadas 10 gotas do Reagente 3 e agitadas com movimentos circulares. Em seguida, foi adicionada 01 medida rasa do Reagente 4 e agitada até dissolver. Após a realização desses processos, as amostras foram levadas no Erlenmeyer ao banho-maria fervente por 30 minutos. Posteriormente, foram retirados os frascos do banho-maria e adicionadas 04 gotas de Fenolftaleína. Em seguida, foi adicionado o Reagente 5, agitando a cada gota adicionada, até surgir a cor rosa. Depois de realizados os processos mencionados acima, aguardou-se o resfriamento da amostra, e a mesma foi completada até atingir $20 \mathrm{ml}$ com água desionisada. 
Foram medidos $05 \mathrm{ml}$ da amostra e transferidos para uma cubeta usada no aparelho fotocolorímetro. Posteriormente, adicionadas 05 gotas do Reagente $\mathbf{1}$ de Ortofosfato, e agitadas. Logo após o processo anterior, foi adicionada 01 medida rasa do Reagente 2, de Ortofosfato, agitada e aguardou-se por 10 minutos. Depois desse tempo, foi zerado o equipamento com a prova em branco e feita a leitura das amostras, onde o resultado lido é a concentração em $\mathrm{ml}^{-1}$ de $\mathrm{PO}_{4}$.

Para expressar o resultado em Fósforo $(\mathbf{P})$, multiplicou-se o resultado lido por 0,3263 .

Assim como o procedimento realizado no fósforo, foram realizadas todas as recomendações descritas pelo manual da empresa AlfaKit.

Mediram-se $5 \mathrm{ml}$ de amostra com a seringa, posteriormente transferidosse para o tubo de vidro com tampa rosqueável. Logo, foi realizada uma prova em branco medindo $05 \mathrm{ml}$ de água desionizada e adicionados os reagentes paralelamente à amostra. Após esse processo, foi adicionada 01 medida rasa do Reagente 1, fechado e agitado. Em seguida, foram adicionadas 03 gotas do Reagente 2, fechado e agitado. Posteriormente a esses procedimentos, foram levados os tubos ao Bloco Digestor, e, quando o mesmo atingiu a temperatura de $100^{\circ} \mathrm{C}$, deixou-se por 1 hora nesta temperatura. Após esse tempo, foi desligado o bloco digestor, e aguardou-se que as amostras atingissem a temperatura ambiente. Em seguida, foi adicionada 01 medida rasa do Reagente 3, fechado e agitado até que houve a diluição.

Após a digestão, mediu-se $1 \mathrm{ml}$ de amostra com a seringa e transferiu-se para outro tubo de vidro com tampa rosqueável. Em seguida, foi adicionada 01 medida rasa do Reagente 1 de Nitrato, fechado e agitado até dissolver parcialmente. Após esse processo, foram adicionadas cuidadosamente com a seringa 02 gotas do Reagente 2 de Nitrato, agitado até dissolver completamente. Posteriormente, foram adicionados vagarosamente $4 \mathrm{ml}$ do Reagente 2 de Nitrato tendo o maior cuidado possível, pois a reação liberava muito calor e poderia causar queimaduras. Dando continuidade aos processos, o recipiente foi fechado e homogeneizado, invertendo o mesmo algumas vezes com cuidado, aguardando-se, após esse processo, 10 minutos. Em seguida, foi zerado o equipamento e feita a leitura das amostras na curva de calibração de Nitrato, o resultado foi lido na forma de $\mathrm{N}_{-} \mathrm{NO}_{3}$ 
Para a realização do ensaio, foi preparada a amostra de diluição, seguindo as recomendações do manual da empresa ALFAKIT. Logo após, dois frascos de DBO utilizados no ensaio foram lavados e cheios com água de diluição e, posteriormente, fechados para evitar a presença de bolhas de ar no interior deles, aos outros dois frascos, foi adicionada água de diluição até a metade. Em seguida, foi adicionada a quantidade de amostra correspondente, conforme a diluição calculada. Foi completado o volume com água de diluição e fechado, evitando a formação de bolhas de ar.

Após esses processos, os frascos 1 (água de diluição) e 3 (amostra diluída) foram levados para a incubadora de $\mathrm{DBO}$ a $20^{\circ} \mathrm{C}$, por um período de cinco dias. Esses frascos foram selados pela adição de água destilada nas rolhas apropriadas. Em seguida, foi determinado o oxigênio dissolvido nos frascos 2 e 4 e anotados os resultados. Após os cinco dias, foi determinado o oxigênio dissolvido nos frascos 1 e 3 que estavam na incubadora.

O frasco 1 foi usado somente para verificação da qualidade da água de diluição, onde não deve haver entre os frascos 1 e 2, após cinco dias, uma depleção de oxigênio superior a $0,2 \mathrm{mg} / \mathrm{l}$ de oxigênio.

1. A amostra 3, após cinco dias, deverá apresentar um residual mínimo abaixo OD de 1mg. É bastante desejável que se procure obter uma diluição que provoque uma depleção de 2,5 a 3,5 mg de OD em cinco dias.

\section{Equação 3:}

$$
\frac{m g}{l} \text { de } 02 \text { de } D B O=\frac{(A-B) \times 100}{\% \text { de diluição }}
$$

Onde:

$A=m g / l$ de OD da amostra instantânea (vidro 4);

$\mathrm{B}=\mathrm{mg} / \mathrm{l}$ de OD da amostra de 05 dias (vidro 3).

A medição da temperatura foi realizada in loco com o auxílio de um termômetro químico durante a coleta de água dos pontos analisados. 


\section{RESULTADOS E DISCUSSÕES}

O Gráfico 1 mostra os resultados das análises com relação à salinidade em cada ponto estudado, e, assim, realizada a sua média.

Gráfico 1 - Resultados da análise de Salinidade.

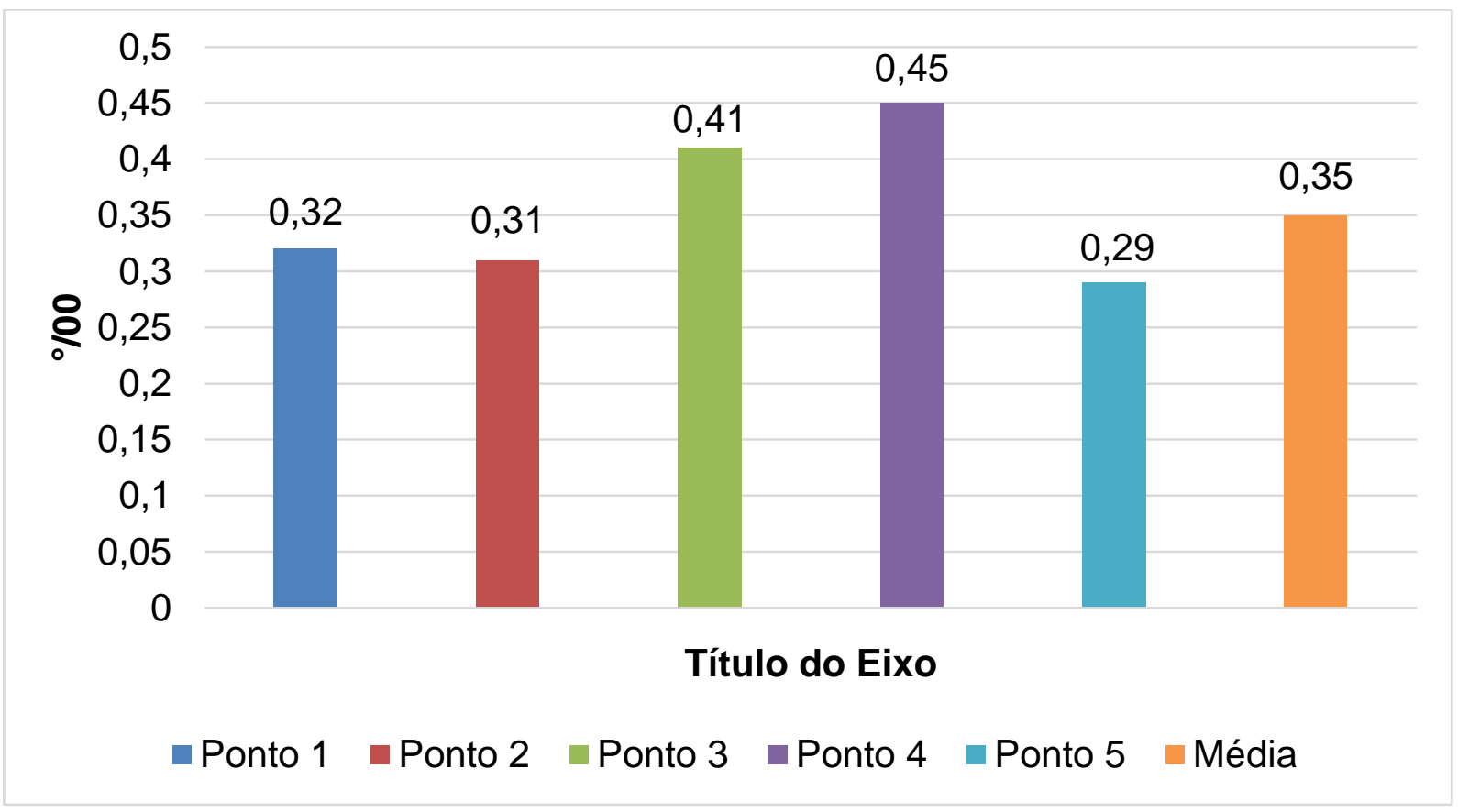

Fonte: Rolim, 2019.

A Resolução CONAMA no 357/2005 utiliza a salinidade para caracterizar o tipo de água de acordo com os sais dissolvidos nela. $O$ valor da média dos cinco pontos ficou abaixo de $0,5 \%$ e, portanto, segundo a resolução CONAMA $n^{\circ}$ 357/2005, podemos classificar a água como doce. 
Gráfico 2 - Resultado do ensaio de pH.

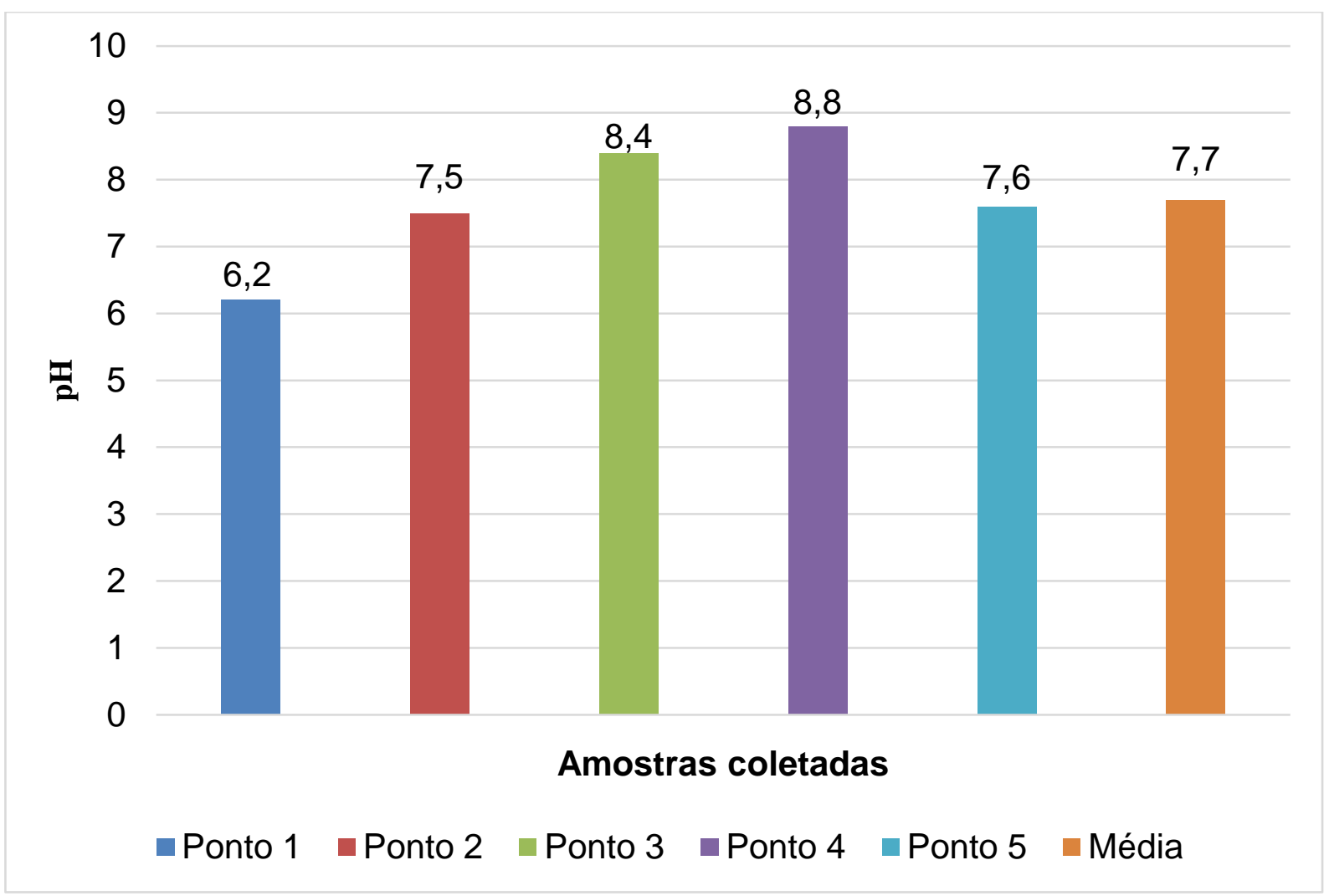

Fonte: Rolim, 2019.

A Resolução CONAMA no 357/2005 estabelece que, para a proteção da vida aquática, o pH deve estar entre 6 e 9. Os valores do gráfico acima variaram de 6,2 a 8,8, obtendo uma média de 7,7, enquadrando-se na classe 1.

O Gráfico 3 apresenta os resultados das análises de turbidez. 
Gráfico 3 - Resultado do ensaio de Turbidez

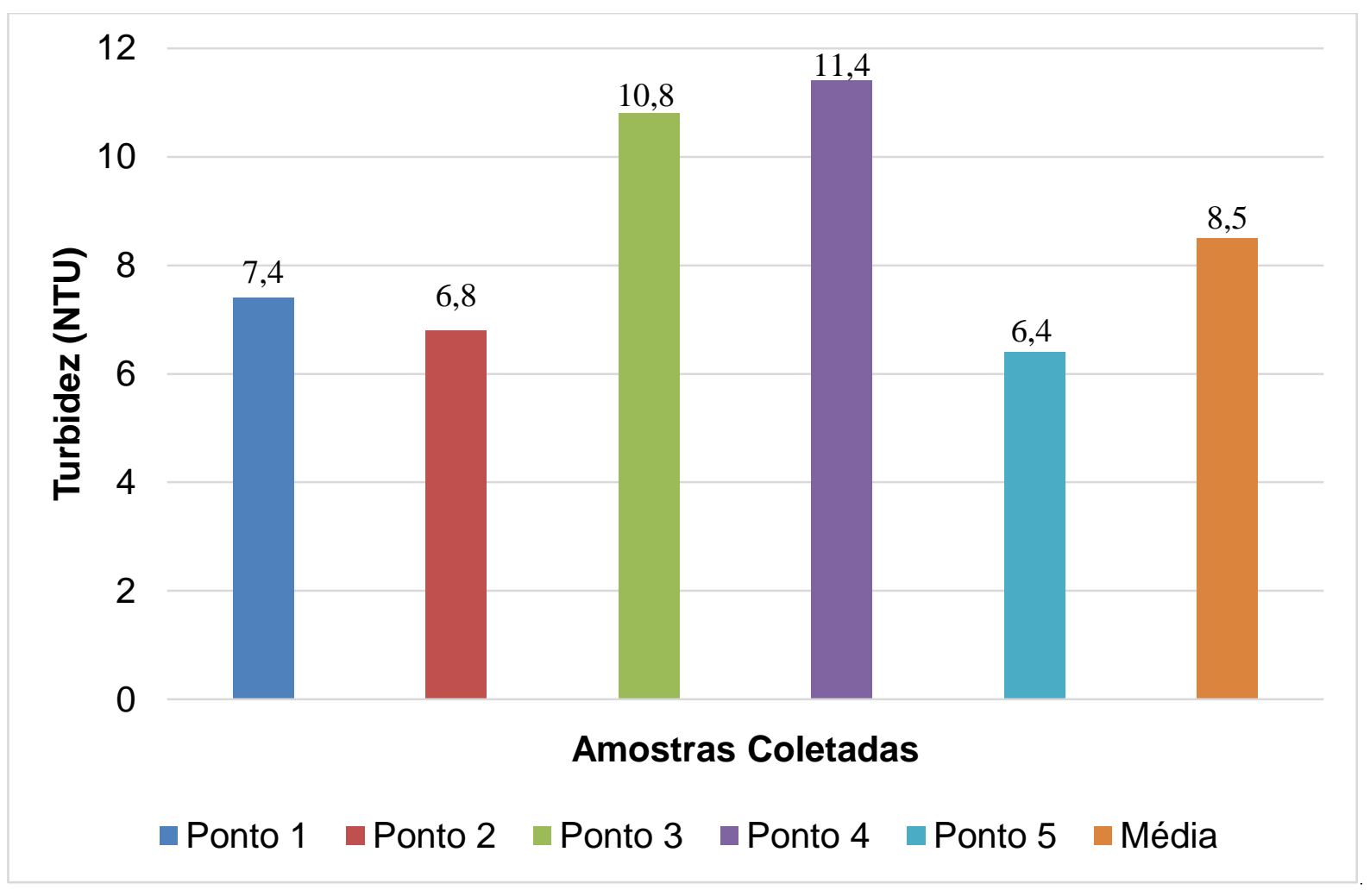

Fonte: Rolim, 2019.

Segundo Siqueira, Aprile e Miguéis (2012), água límpida isenta de turbidez é importante quando se destina direta ou indiretamente ao consumo humano ou processos industriais, sendo que turbidez acima de $5 \mathrm{NTU}$, além de ser notada pelo consumidor e representar uma condição insatisfatória, dificulta o processo de desinfecção/esterilização por tratamento com radiação U.V.

A média dos valores de turbidez obtidos nos cinco pontos analisados foi de 8,5 NTU. Segundo a Resolução do CONAMA no 357/2005, o Valor Máximo Permitido (VMP) é de 40 NTU para as águas doces de classe 1. Podemos verificar, no Gráfico 3, que a média dos valores ficou abaixo, portanto, pode-se classificar o efluente de acordo com os valores de turbidez como classe 1.

O Gráfico 4 mostra os resultados das análises do parâmetro de oxigênio dissolvido. 
Gráfico 4 - Resultados do ensaio de Oxigênio Dissolvido (OD).

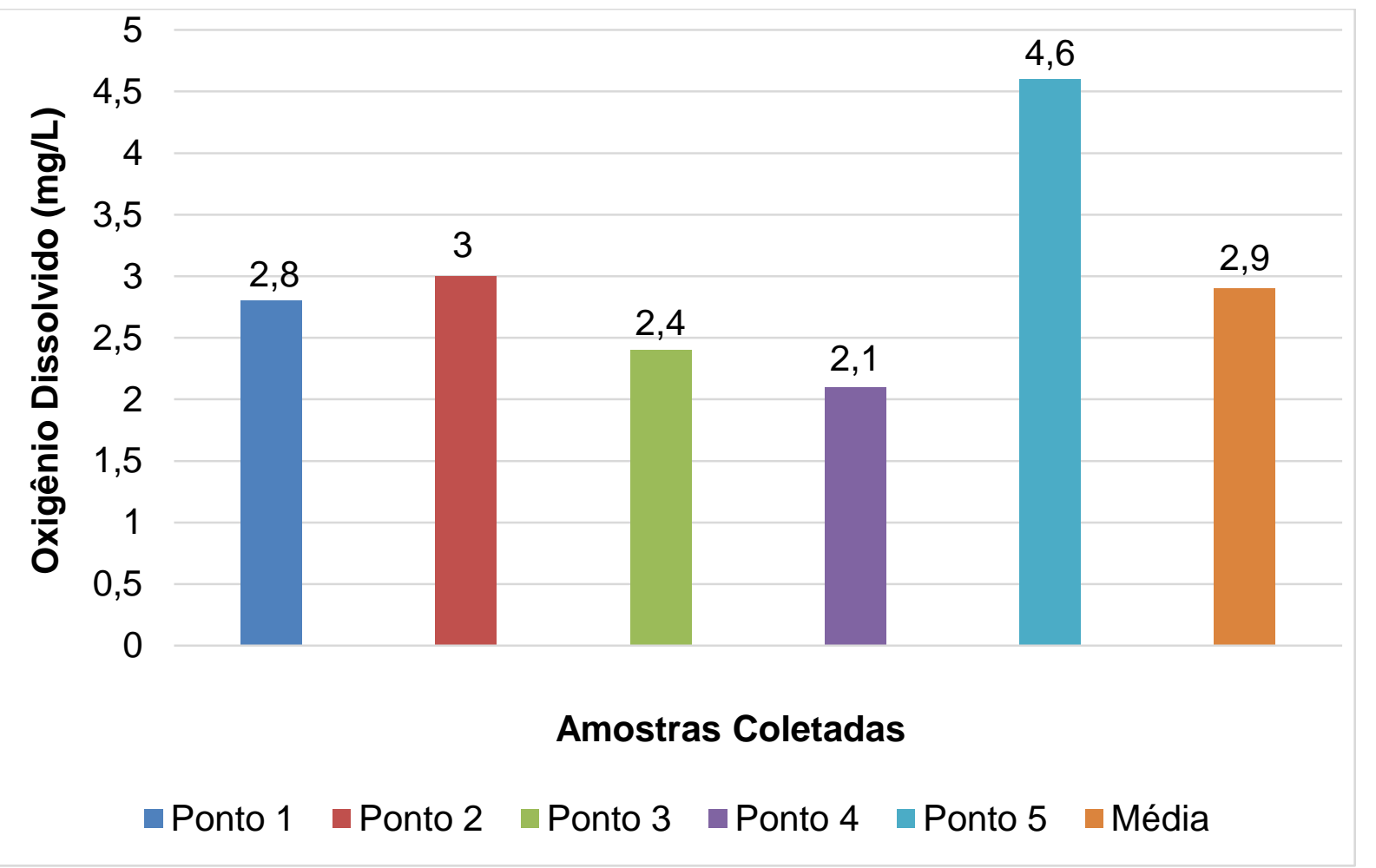

Fonte: Rolim, 2019.

Pode-se observar, no gráfico 4, que os resultados encontrados no ensaio de Oxigênio Dissolvido variaram de 2,1 a 4,6mg/l e uma média de 2,9. Segundo a Resolução do CONAMA no 357/05, o valor permitido para classe 3 é não inferior a 4 $\mathrm{mg} / \mathrm{l}$, portanto não atendendo o valor permitido pela classe, enquadrando-se na classe 4.

Oxigênio dissolvido está ligado diretamente à temperatura, pois a elevação da mesma diminui os teores de oxigênio dissolvido (BRASIL, 2019).

Segundo a Agência Nacional de Águas - ANA, o oxigênio dissolvido é vital para a preservação da vida aquática, já que vários organismos (exemplo, os peixes) precisam de oxigênio para respirar. Portanto, nos pontos de coleta, a água pode ser considerada poluída, uma vez que as concentrações foram inferiores a $5 \mathrm{mg} / \mathrm{l}$ (BRASIL, 2019).

O Gráfico 5 mostra os resultados encontrados referentes à temperatura. 
Gráfico 5 - Resultados obtidos em relação à Temperatura dos pontos analisados.

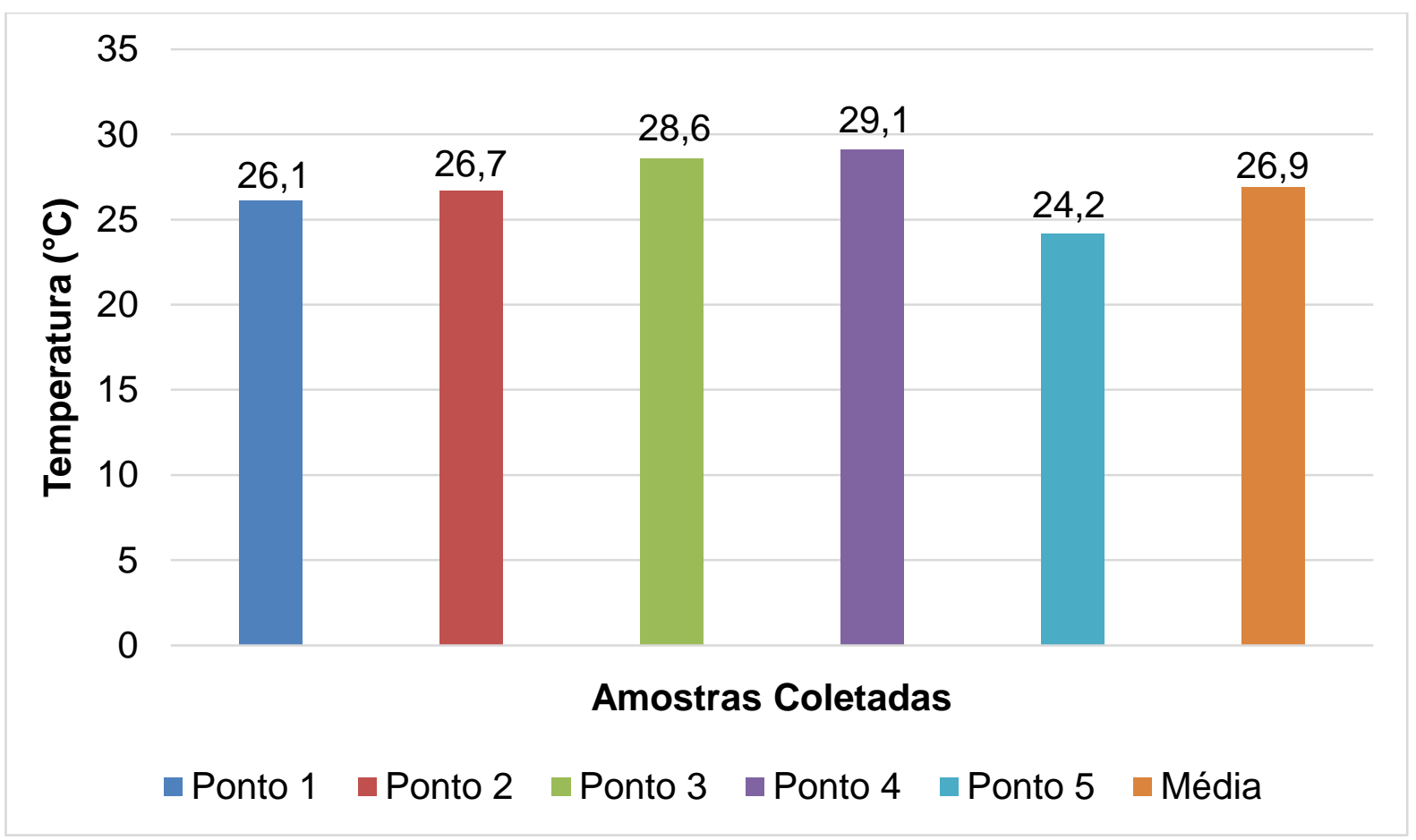

Fonte: Rolim, 2019.

A partir da análise do gráfico 5 , nota-se que os pontos 3 e 4 apresentaram temperaturas superiores aos demais, podendo ser justificada por haver despejo de efluentes identificados pelas galerias destinadas às águas do Açude Grande.

A Gráfico 6 descreve os resultados encontrados nas análises do parâmetro fósforo. 
Gráfico 6 - Resultados obtidos a partir do ensaio do Fósforo.

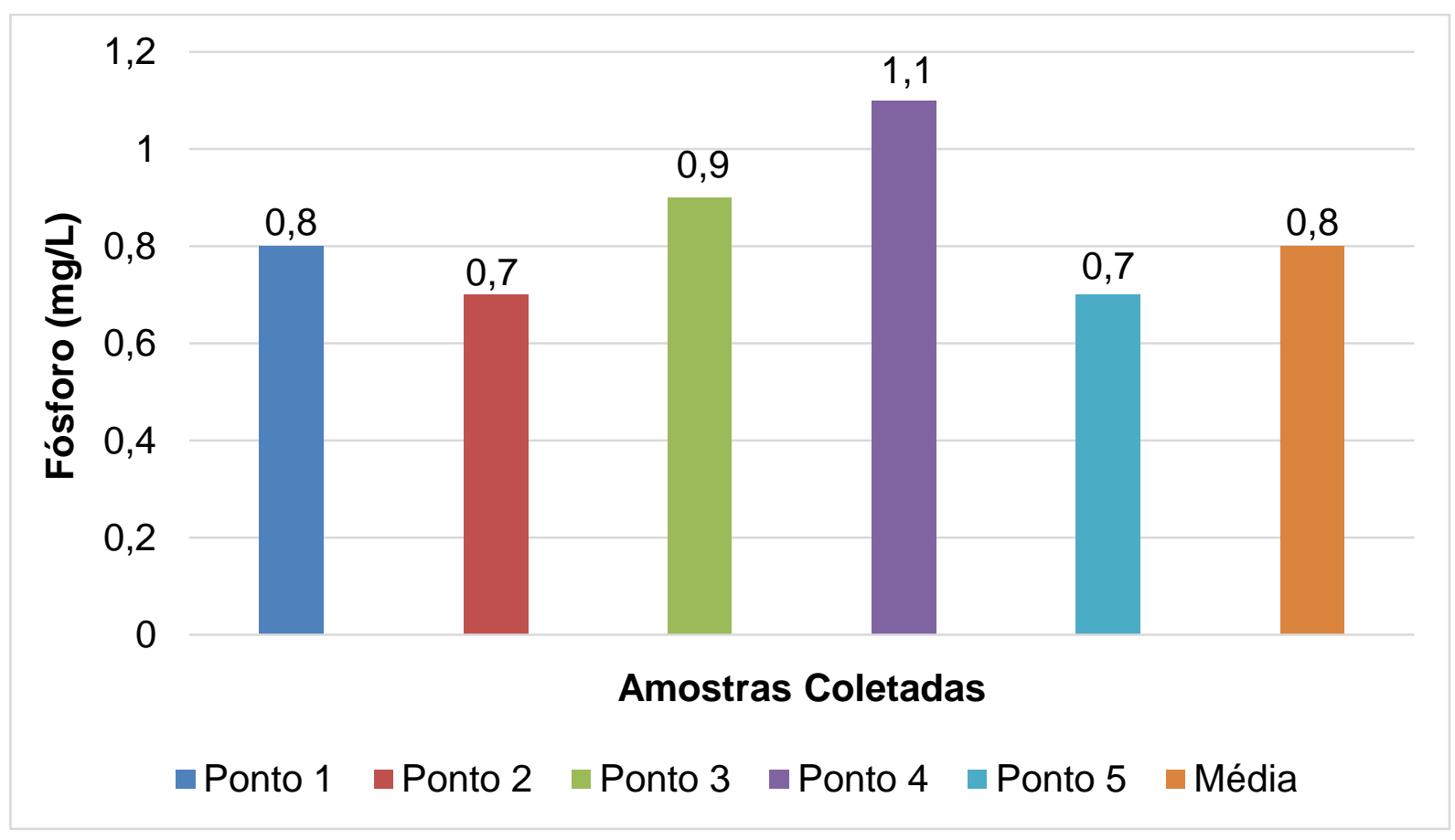

Fonte: Rolim, 2019.

Nota-se que as concentrações de fósforo variam entre 0,7 e $1,1 \mathrm{mg} / \mathrm{l}$ e a média dos pontos foi de 0,8, sendo possível afirmar o indicativo de que o Açude Grande recebe cargas de fósforo acima do valor máximo 0,05 da classe 3 determinado pela resolução CONAMA 357/2005, enquadrando-se na classe 4.

$O$ excesso de fósforo em esgotos sanitários e efluentes industriais pode contribuir com o processo de eutrofização, principalmente em corpos hídricos lênticos, onde a vazão da água é mais baixa (BRASIL, 2016).

O Gráfico 7 mostra os resultados do parâmetro nitrogênio. 
Gráfico 7 - Resultados obtidos a partir do ensaio do Nitrogênio.



Fonte: Rolim, 2019.

De acordo com a resolução CONAMA 357/2005, o valor máximo permitido pela classe 1 é de $10 \mathrm{mg} / \mathrm{l}$. Como se pode observar no gráfico 7 , os valores encontrados para os cinco pontos estudados foram inferiores ao estabelecido pela resolução do CONAMA, sendo assim, o açude pode ser classificados como classe 1.

O principal problema relacionado com altas concentrações de nitrogênio é a eutrofização. Por ser um elemento indispensável para o crescimento de algas e, estando em elevadas concentrações em lagos e represas, pode conduzir a um crescimento exagerado desses organismos, causa interferências aos usos desejáveis do corpo d'água. (GLÓRIA; HORN; HILGEMANN, 2017).

O Gráfico 8 mostra os resultados do parâmetro DBO. 
Gráfico 8 - Resultados obtidos a partir do ensaio de DBO.

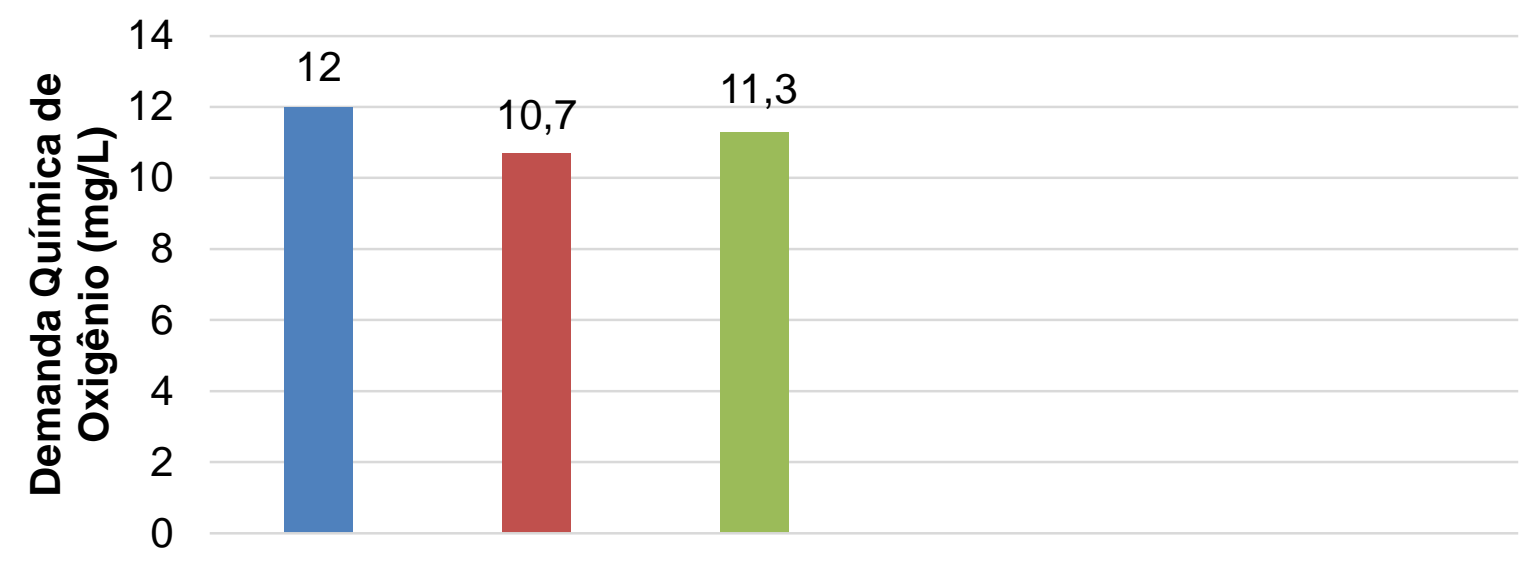

\section{Amostras Coletadas}

- Ponto 1 - Ponto 2 Média

Fonte: Rolim, 2019

Os valores de DBO observados nos pontos 1 e 2 oscilaram entre 10,78 e $12,03 \mathrm{mg} / \mathrm{l}$, obtendo uma média de 11,3. A resolução CONAMA 357/2005 estabelece que, para a classe 3 , os valores não podem exceder $10 \mathrm{mg} / \mathrm{l}$, portanto, caracteriza-se como classe 4.

A DBO exprime o valor da poluição de oxigênio consumida por microrganismos adicionados ao processo. Este parâmetro retrata de forma indireta 0 teor de matéria orgânica nos corpos hídricos (LEITE et al., 2013).

Foram realizadas as médias entre os cinco pontos analisados para cada parâmetro, com o intuito de tornar os valores mais representativos em relação ao açude como o todo. De acordo a Resolução do CONAMA no 357/05, o açude foi classificado como classe 4, pois a média de todos os parâmetros analisados atende às exigências da classe. Apenas alguns parâmetros ficaram dentro dos valores permitidos por outras classes, o $\mathrm{pH}$, temperatura, turbidez e o Nitrato atenderam todas as classes.

O Quadro 1 mostra os resultados das classificações para cada parâmetro. 
Quadro 1 - Classificação.

\begin{tabular}{|l|c|c|c|c|}
\hline \multicolumn{1}{|c|}{ Parâmetro } & Classe 1 & Classe 2 & Classe 3 & Classe 4 \\
\hline Oxigênio dissolvido & Não atende & Não atende & Não atende & Atende \\
\hline pH & Atende & Atende & Atende & Atende \\
\hline DBO & Não atende & Não atende & Não atende & Atende \\
\hline Temperatura & Atende & Atende & Atende & Atende \\
\hline Nitrato & Atende & Atende & Atende & Atende \\
\hline Fósforo total & Não atende & Não atende & Não atende & Atende \\
\hline Turbidez & Atende & Atende & Atende & Atende \\
\hline
\end{tabular}

Fonte: Rolim, 2019.

Classificadas como classe 4, as águas do açude Grande podem ser destinadas para determinados fins. São eles:

- Navegação;

- Harmonia paisagista.

\section{CONCLUSÃO}

Em épocas passadas, o Açude Grande era usado como fonte de abastecimento da cidade de Cajazeiras-PB. Com o crescimento urbano, veio o aumento de lixos e despejos de efluentes, vindo a poluir o açude, desse modo, tornando-o inapropriado para o consumo da população local. Nos tempos onde a seca castiga, se o mesmo estivesse em condições de uso, teria grande importância no abastecimento e em atividades econômicas como: Pesca, plantações e lazer. É devido ao descaso dos poderes públicos junto à sociedade que a água do açude encontra-se degradada e impossibilitada para o uso da população.

Com a ausência da fiscalização, junto à falta de compromisso por parte da gestão pública, as invasões de construções em torno do açude foram primordiais para o despejo de lixos e efluentes, onde a falta de um sistema de saneamento 
adequado, o açude tornou-se um local de despejo de esgotos domésticos e residenciais.

Levando em consideração o estado em que se encontra o açude, o mesmo possui um grande potencial hídrico e, por este motivo, é de grande importância que a população, junto aos gestores públicos, invista em formas de revitalizá-lo, trazendo de volta o benefício do abastecimento em tempos de seca e fonte de renda através das atividades econômicas que dependem do açude.

Em virtude dos fatos mencionados, é de vital importância um projeto de lei municipal que fiscalize construções irregulares nas margens do açude para, assim, evitar contaminações por despejos de resíduos, além de fiscalizar o controle de resíduos sólidos, desviando as galerias de esgotos para uma Estação de Tratamento de Água (ETA), e, por fim, implantação do Plano de Gerenciamento de Resíduos Sólidos (PGRS).

\section{REFERÊNCIAS BIBLIOGRÁFICAS}

ALMEIDA, F. S; FONSECA, J. S. Legislação ambiental, ética e sustentabilidade: a revitalização do Açude Grande de Cajazeiras/PB. Monografia (Especialização em Gestão Ambiental) - Universidade Federal de Campina Grande. Cajazeiras, 2005.

ALMEIDA, J. C. Avaliação do índice de qualidade da água na Lagoa dos Patos. 2013. $52 f$. Monografia (Bacharelado em Engenharia Ambiental e Sanitarista) - Universidade Federal de Pelotas. Pelotas, 2013.

BRAGA, F. P. Avaliação de desempenho de uma estação de tratamento de água do município de Juiz de Fora-MG. 2014. 70f. Monografia (Bacharelado em Engenheiro Sanitarista e Ambiental) - Universidade Federal De Juiz De Fora, Juiz de Fora-MG, 2014.

BRASIL. Agência Nacional Das Águas. Portal da Qualidade das águas. 2019. Disponível em < http://pnqa.ana.gov.br/IndicadoresQA/introdu\%C3\%A7\%C3\%A3o.aspx>.

Acesso em: 20 maio 2019.

BRASIL. Instituto Brasileiro de Geografia e Estatística-IBGE. Paraíba. Cajazeiras. Infográficos: Evolução populacional e pirâmide etária, 2018. Disponível em: < https://www.ibge.gov.br/> Acesso em: 01 de out. de 2018.

BRASIL. Ministério da Saúde. Secretaria de Vigilância Sanitária. Portaria no. 2914 de 12 de Dezembro de 2011. Dispõe sobre os procedimentos de controle e de vigilância da qualidade da água para consumo humano e seu padrão de potabilidade. Diário Oficial da União, Brasília, 2011.

BRASIL. Companhia de Tecnologia e Saneamento Ambiental (CETESB). Apêndice D - Índices de Qualidade de Águas. São Paulo: CETESB, 2019. 
BRASIL. Ministério do Meio Ambiente. Resolução CONAMA 357, de 17 de março de 2005. Disponível em: <http://www.mma.gov.br/port/conama/res/res05/res35705.pdf>. Acesso em: 10 maio 2019.

CAMPOS, José Nison B. Secas e políticas no semiárido: ideias, pensadores e períodos. Estud. av. v. 28, n. 82, p. 65-88, 2014. Disponível em: <http://www.scielo.br/scielo.php?script=sci_arttext\&pid=S0103-40142014000300005>. https://dx.doi.org/10.1590/S0103-40142014000300005

CARVALHO, Ana Paula Monteiro et al., Avaliação dos parâmetros de qualidade da água de abastecimento alternativo no distrito de Jamacaru em Missão Velha-CE. Revista de Iniciação Científica, Tecnológica e Artística. v. 7, n. 1, p. 35-51, 2017.

GLÓRIA, L. P.; HORN, B. C.; HILGEMANN, M. Avaliação da qualidade da água de bacias hidrográficas através da ferramenta do Índice de Qualidade da Água - IQA. Revista Caderno Pedagógico. v. 14, n. 1 , p. 103-119, 2017. http://dx.doi.org/10.22410/issn.19830882.v14i1a2017.1421.

GIRÃO, O. Reconstrução do clima no nordeste brasileiro: secas e enchentes do século XIX. Finisterra. n. 93, p. 29-47, 2012.

LEITE, D. A. N. O. et al., Avaliação dos parâmetros do Índice de Qualidade de Água segundo o modelo estatísticos ARIMA. Holos Environment. v. 13, n. 1, p. 24-39, 2013. http://dx.doi.org/10.14295/holos.v13i1.4641

MARTINS, J. M. F. Análise de qualidade físico-química de água de poço artesiano. 2017. 31f. Monografia (Bacharelado em Química Industrial) - Universidade Estadual da Paraíba. Campina Grande, 2017.

MOUSINHO, A. T. Análise Físico-Química e Microbiológica da Água do Açude de um Município do Estado da Paraíba. 2017. 44f. Monografia (Licenciatura em Química) Universidade Estadual da Paraíba. Campina Grande, 2017.

MOREIRA, E. R. F; LIMA, V. R. P; TARGINO, I. A luta camponesa pela água enquanto uma etapa do processo de construção/consolidação de territórios de esperança. Revista Formação. v. 1, n.15, p. 74-84, 2008. https://doi.org/10.33081/formacao.v1i15.736

NASCIMENTO, J. A. R. Caracterização físico-química e microbiológica de uma água proveniente de ar condicionado. 2017. 39f. Monografia (Licenciatura em Química) Universidade Estadual da Paraíba. Campina Grande, 2017.

OLIVEIRA, K. A. Qualidade da água para consumo humano em solução alternativa de abastecimento no município do cabo de santo agostinho, Pernambuco. 2011. $16 \mathrm{f}$. Monografia (Especialização em saúde pública) - Fundação Oswaldo Cruz. Recife, 2011.

PARRON, L. M.; MUNIZ, D. H. F.; PEREIRA, C. M. Manual de procedimentos de amostragem e análise físico-química de água. Revista EMBRAPA Florestas, v.1, n. 1, p. 1-70, 2011.

PEREIRA, L. D. A. De onde vem a água que nós bebemos? Revista Eletrônica de Ciências. 2012. Disponível em: <http://www.cdcc.sc.usp.br/ciencia/artigos/art_50/agua.html> Acesso em: 13 jun. 2019.

RICHTER, C. A. Água: métodos e tecnologia de tratamento. São Paulo: Blucher/Hemfibra, 2009. $340 \mathrm{p}$.

SCURACCHIO, P. A. Qualidade da água utilizada para consumo em escolas no município de São Carlos - SP. 2010. 59f. Monografia (Mestrado em Alimentos e Nutrição) - Universidade 
Estadual Paulista Júlio De Mesquita Filho. Araraquara, 2010.

SILVA, Aldeni Barbosa da et al. Análise microbiológica da água utilizada para consumo nas escolas de Esperança, Paraíba. Revista Principia. v. 1, n. 1, p. 11-17, 2017.

SIQUEIRA, G. W.; APRILE, F.; MIGUÉIS, A. M. Diagnóstico da qualidade da água do rio Paraupebas (Pará - Brasil). Revista Acta Amazônica, v. 42, n. 3 p. 413-422, 2012.

SIQUEIRA, L. A. Água Fonte da Vida. 2011. 54f. Monografia (Pós-graduação em Ensino de Ciências) - Universidade Tecnológica Federal do Paraná. Medianeira, 2011.

SOARES, A. C. F. Avaliação da qualidade de água tratada distribuída em Campina Grande. 2016. 52f. Monografia (Bacharelado em química industrial) - Universidade Estadual da Paraíba. Campina Grande, 2016.

SOUZA, J. R. de et al. A Importância da Qualidade da Água e os seus Múltiplos Usos: Caso Rio Almada, Sul da Bahia, Brasil. Revista Eletrônica do PRODEMA. v. 8, n. 1, p. 26-45, 2014.

SOUZA, J. A. P. Aspectos gerais da degradação das águas do "Açude Grande" de Cajazeiras-PB. 2015. 26f. Monografia (Licenciatura em Geografia) - Universidade Federal de Campina Grande. Cajazeiras, 2015.

WACHINSKI, M. C. Análise microbiológica da água consumida diretamente de bicas d'água na cidade de Canoinhas/SC. 2013. 62f. Monografia (Licenciatura em Ciências Biológicas) - Universidade Federal de Santa Catarina. Canoinhas, 2013.

YAMAGUCHI, M.U. et al. Qualidade microbiológica da água para consumo humano em instituição de ensino de Maringá-PR. Revista o mundo da saúde. v. 1, n. 1, p. 1-9, 2013. 